\title{
Hepatitis B virus X (HBX) protein upregulates $\beta$-catenin in a human hepatic cell line by sequestering SIRT1 deacetylase
}

\author{
RATAKORN SRISUTTEE ${ }^{1}$, SANG SEOK KOH ${ }^{3,4}$, SU JIN KIM ${ }^{3,4}$, WARAPORN MALILAS ${ }^{1}$, \\ WASSAMON BOONYING ${ }^{1}$, IL-RAE CHO ${ }^{1}$, BYUNG HAK JHUN ${ }^{2}$, MASAFUMI ITO ${ }^{5}$, \\ YOSHIYUKI HORIO ${ }^{6}$, EDWARD SETO ${ }^{7}$, SANGTAEK $\mathrm{OH}^{8}$ and YOUNG-HWA CHUNG ${ }^{1}$
}

\begin{abstract}
${ }^{1}$ WCU, Department of Cogno-Mechatronics Engineering, ${ }^{2}$ Department of Nanomedical Engineering, Pusan National University, Busan; ${ }^{3}$ Immunotherapy Research Center, Korea Research Institute of Bioscience and Biotechnology, Daejeon; ${ }^{4}$ Department of Functional Genomics, University of Science and Technology, Daejeon, Republic of Korea; ${ }^{5}$ Department of Urology, Gifu University Graduate School of Medicine, Gifu; ${ }^{6}$ Department of Pharmacology, Sapporo Medical University, Sapporo, Japan; ${ }^{7}$ H. Lee Moffitt Cancer Center and Research Institute, Tampa, FL, USA; ${ }^{8}$ Department of Advanced Fermentation Fusion Science and Technology, Kookmin University, Seoul, Republic of Korea
\end{abstract}

Received March 6, 2012; Accepted April 17, 2012

DOI: $10.3892 /$ or. 2012.1798

\begin{abstract}
Hepatitis B virus X (HBX) protein has been reported to induce upregulation of $\beta$-catenin, a known protooncogene, in p53-knockout and p53-mutant hepatic cell lines both in a GSK-3 3 -dependent manner and via interaction with adenomatous polyposis coli, which results in protection from $\beta$-catenin degradation. In this study, we describe a novel mechanism for HBX-mediated upregulation of $\beta$-catenin. We observed that HBX interacts with SIRT1, a class III histone deacetylase. Furthermore, the presence of HBX attenuated the interaction between SIRT1 and $\beta$-catenin, leading to protection of $\beta$-catenin from the inhibitory action of SIRT1. Reduction of SIRT1 with siRNA or suppression of SIRT1 activity with nicotinamide upregulated $\beta$-catenin protein levels. In contrast, enhancement of SIRT1 activity with resveratrol reduced $\beta$-catenin protein levels. Furthermore, in Hep3B cells stably expressing HBX, overexpression of SIRT1 or treatment with resveratrol enhanced sensitivity to doxorubicin-induced apoptosis, indicating that upregulation of SIRT1 could be a therapeutic strategy for HBV-related hepatocellular carcinoma. Based on these results, we propose that HBX upregulates $\beta$-catenin by sequestering SIRT1, which leads to anticancer drug treatment resistance.
\end{abstract}

Correspondence to: Professor Young-Hwa Chung, WCU, Department of Cogno-Mechatronics Engineering, Pusan National University, Busan 609-735, Republic of Korea

E-mail: younghc@pusan.ac.kr

Key words: hepatitis B virus X, SIRT1, $\beta$-catenin, doxorubicin, apoptosis

\section{Introduction}

The human hepatitis B virus (HBV) induces acute and chronic hepatitis and is closely associated with liver cancer $(1,2)$. Among the 4 proteins derived from the HBV genome, the hepatitis B virus X (HBX) protein is involved in multiple signaling pathways associated with cell survival and proliferation. The cell signal transduction pathways that are activated by HBX include Jak1/Stat3, the PI-3 kinase pathways (3-6) and the Ras/Raf/MAPK signaling cascade which leads to NF- $\kappa B$ activation $(7,8)$. HBX expression also increases reactive oxygen species (ROS) via calcium signaling and cellular kinases, which results in activation of the transcription factors NF- $\kappa B$ and Stat3 (3). In addition, HBX enhances Statl activity, which results in Type I IFN production (9). However, HBX-mediated downregulation of Type I IFN receptor inhibits extracellular IFN signal transduction (10). Other studies have shown that HBV-induced oxidative stress also stimulates the translocation of Raf-1 and a dominant negative PAK mutant and Src inhibitors abolish HBX-mediated Raf-1 mitochondrial translocation (11). We have previously reported that HBX induces upregulation of Foxo4, leading to the alleviation of oxidative stress through the JNK signaling pathway, which may provide a favorable environment for the survival of HBV-infected hepatic cells (12).

SIRT1, a member of the class III histone deacetylases, has been conserved throughout evolution from yeast to human (13) and is the key molecule responsible for extending life span in response to caloric restriction (14-16). SIRT1 can deacetylate not only histones (17) but also non-histone proteins including NF-кB p65 (18), p53 (19), Ku70 (20) and Foxo3a (21). It has been reported that SIRT1 expression is regulated at multiple levels and SIRT1 activity is regulated by cellular factors. Interaction of deleted in breast cancer (DBC)1 with SIRT1 inhibits SIRT1 activity, leading to a reduction of p53 deacetylation, which 
indicates that $\mathrm{DBC} 1$ acts as a negative SIRT1 regulator $(22,23)$. The active regulator of SIRT1 (AROS), identified as a SIRT1 interacting partner in a yeast two-hybrid screen, increases the enzymatic efficiency of SIRT1 through a conformational change (24). It has been also been demonstrated that interaction of the human immunodeficiency virus (HIV) Tat protein with SIRT1 blocks SIRT1 activity, similarly to the action of DBC1 (25).

The Wnt/ $\beta$-catenin signaling pathway plays an important role in cell proliferation, differentiation, and oncogenesis $(26,27)$. In particular, abnormal upregulation of $\mathrm{Wnt} / \beta$-catenin activity has frequently been detected as an early event in many cancers (28). The $\beta$-catenin protein levels are normally regulated in part through the protein's targeted decay, which is mediated through a glycogen synthase kinase-3 $\beta$ (GSK-3 $\beta$ )dependent or -independent pathway (29). In the absence of Wnt signaling, cytoplasmic $\beta$-catenin is sequentially phosphorylated by casein kinase and GSK-3 $\beta$, which form a complex with adenomatous polyposis coli (APC) and axin, resulting in the degradation of $\beta$-catenin via a ubiquitinationdependent mechanism. Activation of the receptor by its Wnt ligands negatively regulates GSK-3 $\beta$, leading to the stabilization of $\beta$-catenin in the cytoplasm (30). During Wnt/ $\beta$-catenin signaling, $\beta$-catenin is translocated into the nucleus. There, it forms a complex with members of the T cell factor/lymphocyte enhancer factor(TCF/LEF) family of transcription factors, and thereby activates the expression of $\beta$-catenin responsive genes, such as cyclin-D1, $c$-Jun, $c-M y c$, and peroxisome proliferatoractivated receptor- $\delta(P P A R-\delta)(31-34)$, which play important roles in oncogenesis.

This study was undertaken to determine the novel oncogenic mechanism by which HBX functions in the proliferation and survival of hepatocellular carcinoma cells. We herein report that HBX binds to SIRT1. The interaction of HBX with SIRT1 protects $\beta$-catenin from the inhibitory action of SIRT1, leading to upregulation of $\beta$-catenin protein and activity. Therefore, we propose that HBX upregulates $\beta$-catenin by sequestering SIRT1 in a Wnt signaling-independent manner.

\section{Materials and methods}

Cell cultures and transient transfection. HEK293 T cells, parental Hep3B, and Hep3B cells stably expressing vector (Hep3B-Vec) or HBX (Hep3B-HBX) were cultured in DMEM supplemented with $10 \%$ FBS and $1 \%$ penicillin and streptomycin. The cells were plated at $5 \times 10^{5}$ cells/well of a 6 -well plate $24 \mathrm{~h}$ before transfection and the cells were transfected with 3-5 $\mu \mathrm{g}$ of DNA using Lipofectamine 2000 (Invitrogen, Carlsbad, CA). Protein expression was examined by immunoblotting $48 \mathrm{~h}$ after transfection.

Reagent, antibodies, and plasmids. Nicotinamide, resveratrol, and wortmannin were purchased from Calbiochem (San Diego, CA, USA). LiCl was obtained from Sigma-Aldrich (St. Louis, MO). Anti-SIRT1, anti-Myc, anti-histone H3 and anti-actin antibodies used for immunoblotting were purchased from Santa Cruz Biotechnology (Santa Cruz, CA). Anti- $\beta$-catenin antibody was purchased from BD Biosciences (San Jose, CA). Anti-Akt, anti-phospho-Akt (Ser-473), anti-GSK-3 $\beta$, and antiphospho-GSK-3 $\beta$ (Ser-9) antibodies were obtained from Cell
Signaling Technology (Danvers, MA). For transient expression of proteins, pCMV-Myc-HBX (12), pEGFP-SIRT1 (35), pCDNA3.1-Myc-SIRT1 (36), and pCMV-Flag- $\beta$-catenin (37) were transfected into cells.

siRNA transfection. Cells were trypsinized and incubated overnight to reach 60-70\% confluence before siRNA transfection. SIRT1 siRNA (100 nM; sense, 5'-ACUUUGCU GUAACCCUGUA (dTdT)-3' and antisense, 5'-UACAGGGU UACAGCAAAGU (dTdT)-3') (Bioneer Corporation, Daejeon, Korea), which has been described elsewhere (24) or negative control siRNA (Bioneer Corporation) was mixed with Lipofectamine 2000 (Invitrogen). The cells were incubated with the transfection mixture for $6 \mathrm{~h}$, and then rinsed with DMEM containing $10 \%$ serum. The cells were incubated for $48 \mathrm{~h}$ before harvest.

Immunoprecipitation and immunoblotting. For immunoblotting, cells were harvested and lysed with lysis buffer $(150 \mathrm{mM}$ $\mathrm{NaCl}, 1 \% \mathrm{NP}-40$, and $50 \mathrm{mM}$ Tris- $\mathrm{HCl}, \mathrm{pH} 7.5)$ containing $0.1 \mathrm{mM} \mathrm{Na} \mathrm{VO}_{3}, 1 \mathrm{mM} \mathrm{NaF}$ and protease inhibitors (SigmaAldrich). Proteins from whole cell lysates were resolved on $10 \%$ or $12 \%$ SDS-PAGE gels, and then transferred to nitrocellulose membranes. Primary antibodies were used at 1:1,000 or 1:2,000 dilutions, and horseradish peroxidase-conjugated secondary antibodies were used at a 1:2,000 dilution in $5 \%$ nonfat dry milk. For immunoprecipitation, cells were harvested after $48 \mathrm{~h}$ of transfection, and the cell debris was removed by centrifugation at $10,000 \mathrm{~g}$ for $10 \mathrm{~min}$ at $4^{\circ} \mathrm{C}$. Cell lysates were pre-cleared with $25 \mu \mathrm{l}$ of protein $\mathrm{A} / \mathrm{G}$ agarose and incubated with the appropriate primary antibody and protein A/G agarose for $1 \mathrm{~h}$ at $4^{\circ} \mathrm{C}$. After 3 washes with lysis buffer, the precipitates were loaded on SDS-PAGE gels and analyzed by immunoblotting with the appropriate antibodies. After a final washing, nitrocellulose membranes were exposed to enhanced chemiluminescence using the LAS 3000 (Fujifilm, Tokyo, Japan).

Luciferase reporter assay. HEK293T and Hep3B cells were transfected with pCMV-Myc-HBX, pEGFP-SIRT1, or pCDNA3.1-Myc-SIRT1 plasmid in the presence of the TOPFlash-, or FOPFlash- luciferase reporter vector. To normalize transfection efficiency, a pGK- $\beta$ gal vector that constitutively expresses $\beta$-galactosidase from a phosphoglucokinase promoter was included in the transfection mixture. At $48 \mathrm{~h}$ post-transfection, cells were washed with cold PBS and lysed in lysis solution [25 mM Tris (pH 7.8), 2 mM EDTA, 2 mM DTT, 10\% glycerol, and 1\% Triton X-100]. Luciferase activity was measured using a luminometer with a Luciferase kit (Promega Corporation, Madison, WI).

MTT assay. In accordance with the manufacturer's instructions (Promega), dye solution containing tetrazolium was added to the cells and incubated for $4 \mathrm{~h}$. The absorbance of the formazan produced by living cells was measured at $570 \mathrm{~nm}$.

\section{Results}

HBX upregulates $\beta$-catenin in a human $p 53^{-/}$hepatic cell line. The frequent observation of abnormal accumulations of 

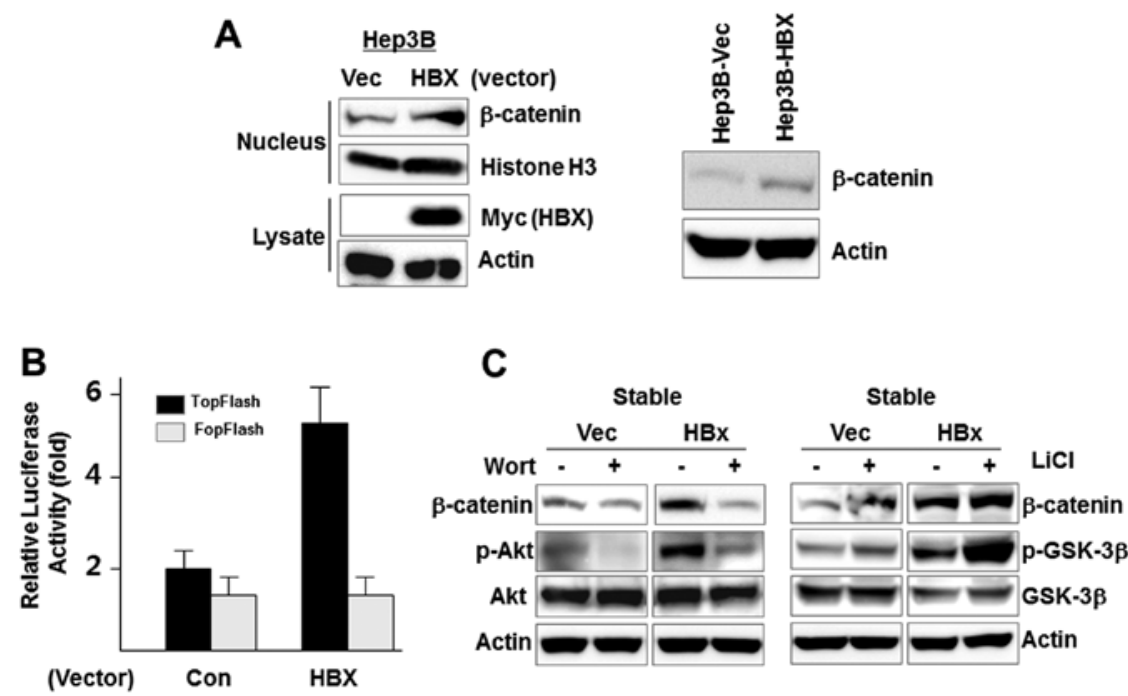

Figure 1. HBX increases $\beta$-catenin protein levels and transcriptional activity in Hep3B cells. (A) Nuclear extracts were prepared as previously described (52) from Hep3B cells transiently transfected with a control vector or a HBX-expressing vector (pCMV-Myc-HBX). Cell lysates from Hep3B-Vec and Hep3B-HBX cells were prepared and separated by a $10 \%$ SDS PAGE gel. The expression of $\beta$-catenin was detected by immunoblotting with anti- $\beta$-catenin antibody. (B) Hep3B cells were transfected with pCMV-HBX or pCMV-Myc plasmid in the presence of the pTopFlash or pFopFash luciferase reporter vector. At $48 \mathrm{~h}$ post-transfection, luciferase activity was measured and the transfection efficiency was normalized with $\beta$-galactosidase vector (pGK- $\beta$-gal). The results shown are the average of triplicate wells. Error bars indicate standard deviation. (C) Hep3B-Vec and Hep3B-HBX cells were treated with wortmannin (Wort; $30 \mu \mathrm{M})$ or $\mathrm{LiCl}(20 \mathrm{mM})$ for $24 \mathrm{~h}$. Akt or GSK-3 $\beta$ activation was determined by its phosphorylation status and the expression of $\beta$-catenin was detected by immunoblotting using anti- $\beta$-catenin antibody.
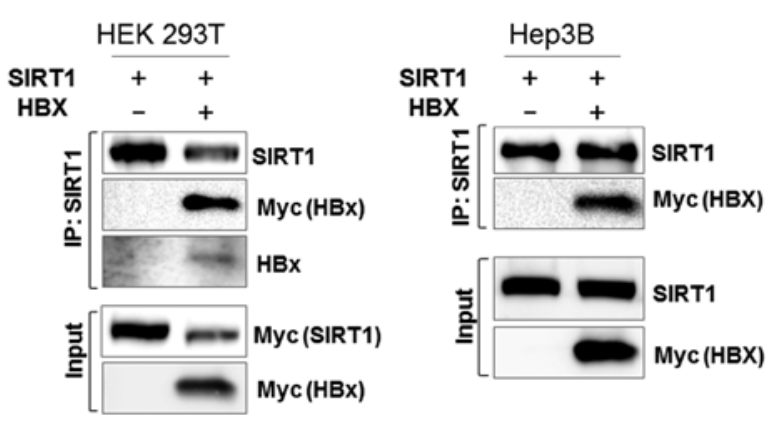

Figure 2. HBX binds to SIRT1 in vivo. HEK293T and Hep3B cells were transfected with pCMV-Myc-HBX $(2 \mu \mathrm{g})$ and pCDNA3.1-Myc-SIRT1 $(2 \mu \mathrm{g})$ plasmids. For immunoprecipitation, the cells were harvested $48 \mathrm{~h}$ post-infection and anti-SIRT1 antibody $(1 \mu \mathrm{g})$ was added after pre-clearing the cell lysate. The cell lysates were then incubated for $1 \mathrm{~h}$ under agitation and ProteinA/G-coupled agarose beads $(20 \mu \mathrm{l})$ were added. After extensive washing, the immunocomplexes were separated by a $12 \%$ SDS-PAGE gel and the HBX binding was detected by immunoblotting with anti-Myc or antiHBX antibodies.

$\beta$-catenin in hepatocellular carcinoma suggests that the upregulated $\beta$-catenin may be attributed to the oncogenic activity of HBX protein in HBV-associated hepatocellular carcinoma (38). To address this possibility, we transiently introduced an HBX expression vector into Hep3B cells, which lack the p53 gene and separated the cytoplasmic and nucleic fractions. As shown in Fig. 1A, more $\beta$-catenin protein was detected in the nucleus of Hep3B cells that were transiently transfected with pCMV-Myc-HBX vector compared to Hep3B cells transiently transfected with a control vector. When we examined $\beta$-catenin protein levels in Hep3B cells stably expressing HBX (Hep3B-HBX) and in Hep3B cells with a control vector (Hep3B-Vec), we also found that the presence of HBX increased $\beta$-catenin protein levels in the cell lysates (Fig. 1A). In addition, to examine whether the HBX-mediated increase in $\beta$-catenin protein levels leads to functional activation and binding to the $\beta$-catenin/TCF binding element in the nucleus, we introduced a TopFlash luciferase plasmid controlled by the $\beta$-catenin/ TCF-4 complex. As shown in Fig. 1B, the presence of HBX significantly enhanced $\beta$-catenin-mediated transcriptional activity in Hep3B cells while the introduction of HBX with FopFlash luciferase vector carrying a mutant TCF binding site failed to enhance $\beta$-catenin-mediated transcriptional activity. Next, to examine whether HBX utilizes Akt or GSK-3 $\beta$ protein as an upstream molecule in $\beta$-catenin upregulation, we treated Hep3B-Vec and Hep3B-HBX cells with wortmannin, an Akt inhibitor, or $\mathrm{LiCl}$, a GSK-3 $\beta$ inhibitor. Wortmannin treatment inhibited Akt activity and reduced $\beta$-catenin protein levels in both cell lines (Fig. 1C). $\mathrm{LiCl}$ treatment inhibited GSK-3 $\beta$ as expected and increased $\beta$-catenin levels in both cell lines (Fig. 1C). This result indicates that HBX-mediated upregulation of $\beta$-catenin utilizes Akt and GSK-3 $\beta$, which are upstream of Wnt signaling.

HBX can interact with SIRT1 in vivo. Although crucial pleitropic functions of SIRT1 in many biological process including stress response, apoptosis, and cellular metabolism have been well documented (39), SIRT1, a Class III histone deacetylase, has recently been implicated in tumor formation and suppression to a greater extent. For this reason, many studies have illustrated the regulation of SIRT1 expression and activity. Reports have shown that the enzymatic activity of SIRT1 may be modulated by the interactions of cellular proteins, such as DCB1 $(22,23)$ and AROS (24). In addition, a viral regulatory protein has been shown to hijack and control SIRT1 enzyme activity for immune modulation. The HIV Tat protein has been reported to directly interact with the histone deacetylase (HDAC) domain of SIRT1, resulting in hyperactivation of 
A

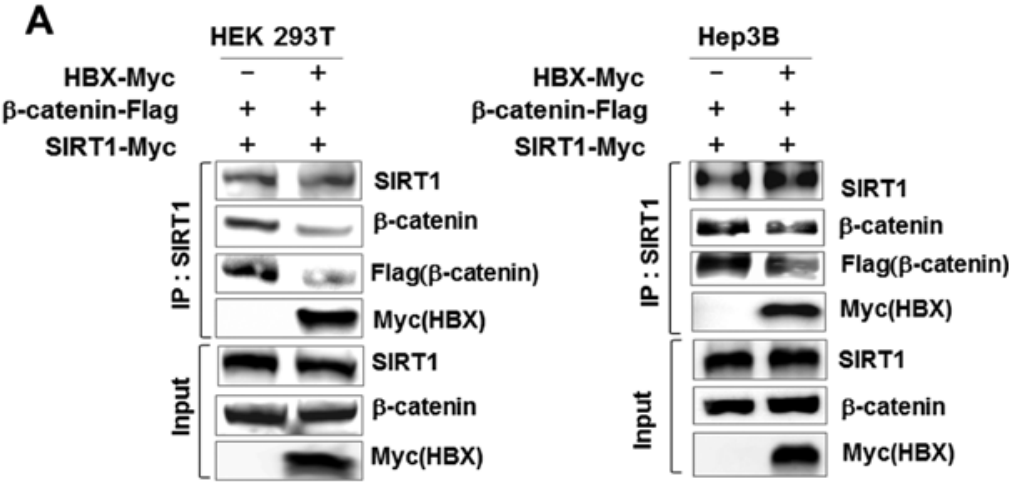

B

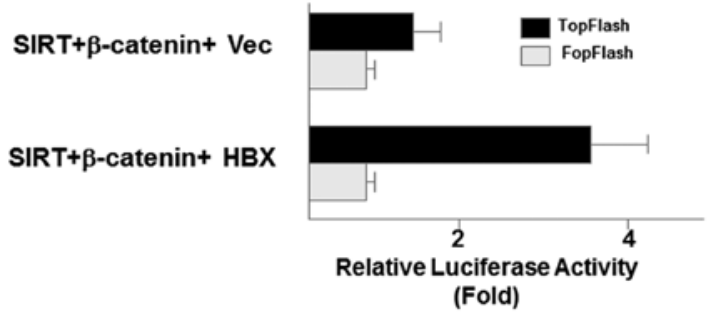

Figure 3. HBX weakens the interaction between SIRT1 and $\beta$-catenin. (A) HEK293T and Hep3B cells transfected with pCMV-Myc-HBX (2 $\mu \mathrm{g})$, pCMVFlag- $\beta$-catenin $(2 \mu \mathrm{g})$ and pCDNA3.1-Myc-SIRT1 $(2 \mu \mathrm{g})$ plasmids were harvested at $48 \mathrm{~h}$ post-infection for immunoprecipitation. The cell lysates were added with an anti-SIRT1 antibody $(1 \mu \mathrm{g})$ and incubated for $1 \mathrm{~h}$ under agitation followed by the addition of Protein A/G-coupled agarose (20 $\mu \mathrm{l})$. After extensive washing, the immunocomplexes were separated by $12 \%$ SDS-PAGE, and the levels of $\beta$-catenin, SIRT1 and HBX protein were detected by immunoblotting with the corresponding antibodies. (B) Hep3B cells were transfected with pCMV-Myc-HBX, pCMV-Flag- $\beta$-catenin and pCDNA3.1-Myc-SIRT1 plasmids in the presence of the pTopFlash or pFopFlash luciferase reporter vector. At $48 \mathrm{~h}$ post-transfection, luciferase activity was measured and transfection efficiency was normalized to a constitutive $\beta$-galactosidase expression plasmid (pGK- $\beta$-gal). The results shown are the average of triplicate wells. Error bars indicate standard deviation.

NF- $\kappa \mathrm{B}$ responsive genes and promotion of immune-activating and pro-inflammatory cytokines by blocking the ability of SIRT1 to deacetylate the NF-kB p65 subunit at lysine 310 (25). Based on this line of evidence, we examined whether HBX interacts with SIRT1 and modulates SIRT1 activity as was observed with the Tat protein. After HEK293T cells were transiently co-transfected with SIRT1 and HBX expression vectors, the cell lysates were immunoprecipitated with antiSIRT1 antibody and immunoblotted with anti-HBX antibodies (an anti-Myc antibody or polyclonal anti-HBX antibodies). As shown in Fig. 2, HBX protein was detected in the immune complex, indicating that HBX interacts with SIRT1 in vivo. Furthermore, to examine whether the interaction between SIRT1 and HBX can be reproduced in Hep3B cells, we co-expressed SIRT1 and HBX in Hep3B cells. After the SIRT1 protein was immunoprecipitated with an anti-SIRT1 antibody, HBX was detected in the immune complex, confirming the interaction between HBX and SIRT1 in Hep3B cells.

HBX attenuates the interaction between SIRTI and $\beta$-catenin. It has been reported that SIRT1 binds to $\beta$-catenin both in vitro and in vivo, and results in inhibition of $\beta$-catenin transcriptional activity in a mouse colon cancer model (40). Our results in Fig. 2 display that HBX interacts with SIRT1 in vivo. Based on this evidence, we hypothesize that the presence of HBX weakens the interaction between SIRT1 and $\beta$-catenin, leading to the release of $\beta$-catenin from SIRT1 inhibition. To test our hypothesis, we introduced HBX, $\beta$-catenin, and SIRT1 plasmids in HEK293T and Hep3B cells. At $48 \mathrm{~h}$ posttransfection, the cell lysates were immunoprecipitated with
anti-SIRT1 antibody and the level of $\beta$-catenin that co-precipitated with the immunocomplex was examined in the absence or presence of HBX. As shown in Fig. 3A, in both Hep3B cells and HEK293T cells, lower levels of $\beta$-catenin protein were detected in the immunocomplexes in the presence of HBX than in the absence of HBX. Moreover, when we compared $\beta$-catenin transcriptional activity in Hep3B cells transiently transfected with HBX, $\beta$-catenin and SIRT1 plasmids to the activity of Hep3B cells transiently transfected with $\beta$-catenin and SIRT1 plasmids, we discovered that the presence of HBX enhanced $\beta$-catenin transcriptional activity compared to the activity in the absence of HBX (Fig. 3B). The results support our hypothesis that HBX attenuates the interaction between SIRT1 and $\beta$-catenin, leading to the protection of $\beta$-catenin from the inhibitory action of SIRT1.

SIRT1 regulates $\beta$-catenin protein levels and activity in Hep3B-HBX cells. Since several studies have reported that ectopic induction of SIRT1 significantly reduced tumor formation, proliferation (41), and mouse morbidity in a $\beta$-catenin-driven mouse model of colon cancer (40), we speculated whether SIRT1 also functions as a suppressor of tumorigenesis through repression of $\beta$-catenin in our HBX-expressing hepatic cell line. Therefore, to examine whether SIRT1 expression or activity affects $\beta$-catenin protein levels in Hep3B-Vec and Hep3B-HBx cells, we transfected the cells with SIRT1 siRNA, nicotinamide (an inhibitor of SIRT1 activity) or resveratrol (an activator of SIRT1 activity). As shown in Fig. 4A, suppression of SIRT1 with siRNA resulted in upregulation of $\beta$-catenin protein levels. In addition, nico- 

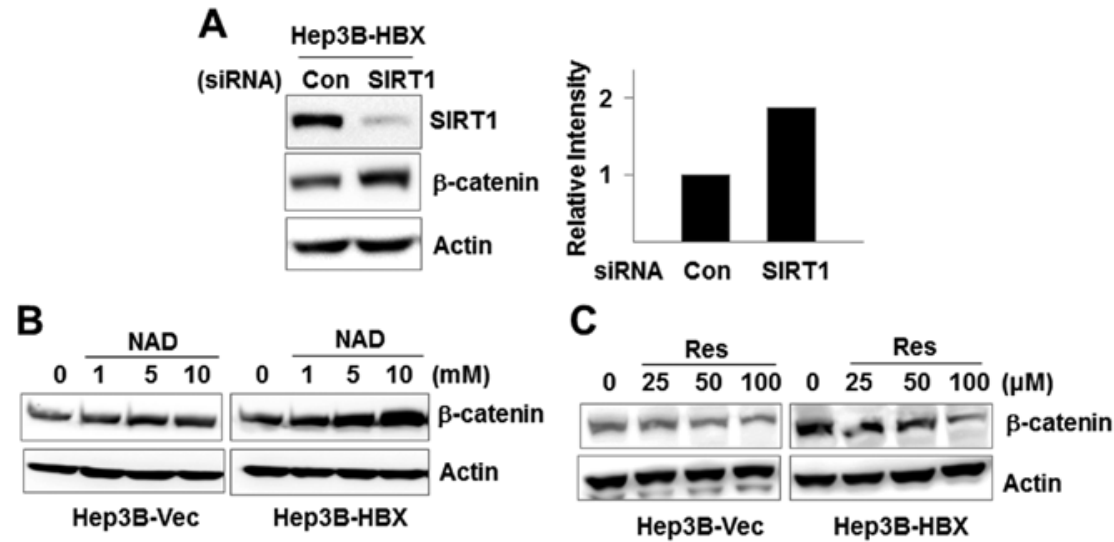

Figure 4. SIRT1 protein levels and activity modulate $\beta$-catenin expression. (A) SIRT1 and $\beta$-catenin protein levels were detected in cell lysates prepared from Hep3B-HBX cells transfected with SIRT1 siRNA $(100 \mathrm{nM}) 48 \mathrm{~h}$ post-transfection. Expression levels were determined by immunoblotting with anti-SIRT1 and anti- $\beta$-catenin antibodies. (B,C) Hep3B-HBX cells were treated with different concentrations of nitocinamide (NAD; 1,5 and $10 \mathrm{mM}$ ) or resveratrol (Res; $25,50$ and $100 \mu \mathrm{M})$ for $24 \mathrm{~h}$ and the expression of $\beta$-catenin was detected by immunoblotting.
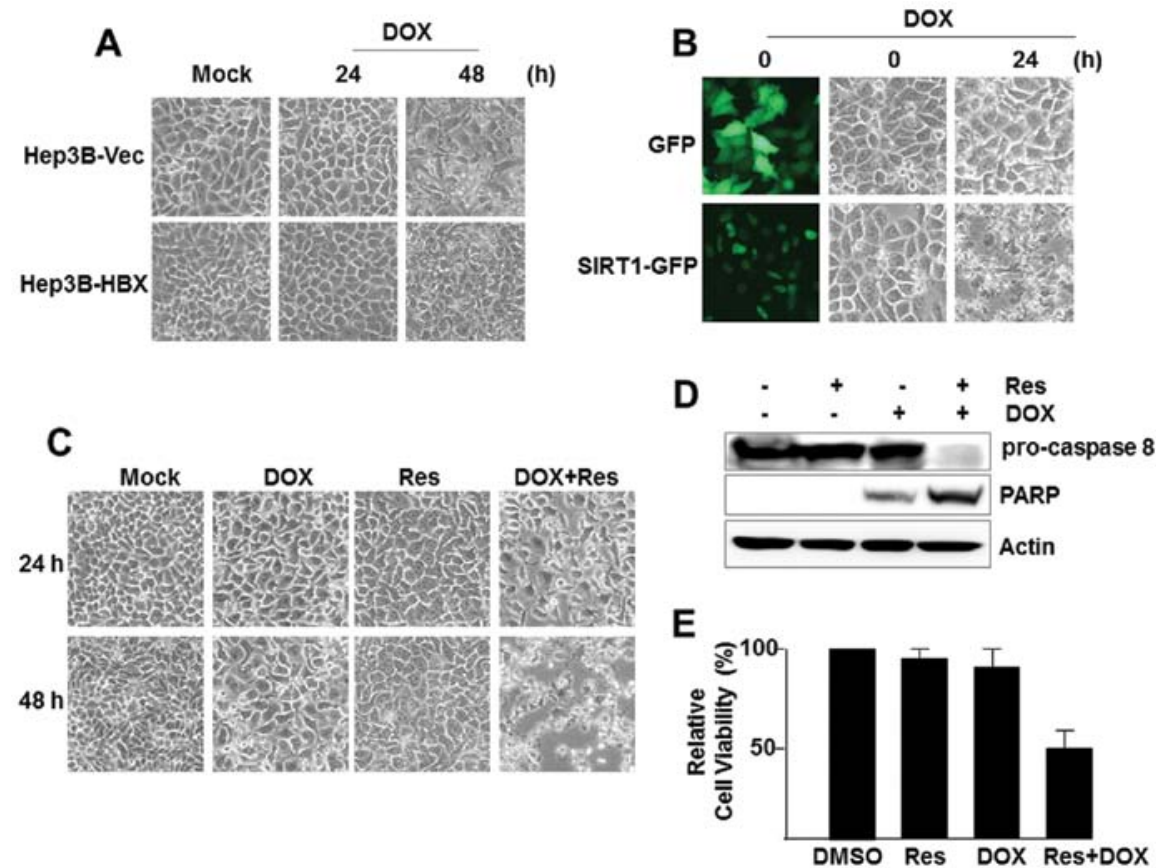

Figure 5. Upregulation of SIRT1 sensitizes Hep3B-HBX cells to doxorubicin-induced apoptosis. (A) Hep3B-Vec and Hep3B-HBX cells were treated with doxorubicin (DOX; $500 \mu \mathrm{g} / \mathrm{ml}$ ) and cell viability was observed under microscopy for $48 \mathrm{~h}$. (B) Hep3B-HBX cells were transfected with pEGFP-SIRT or a control vector and then treated with doxorubicin $(500 \mu \mathrm{g} / \mathrm{ml})$ for $48 \mathrm{~h}$. Transfection efficiency was measured by GFP expression under a fluorescence microscopy. Cell viability was observed under light microscopy for $48 \mathrm{~h}$. (C-E) Hep3B-HBX cells were treated with resveratrol and doxorubicin or doxorubicin alone for $48 \mathrm{~h}$. Cell viability was measured by light microscopy or the MTT assay.

tinamide treatment increased the levels of $\beta$-catenin proteins while resveratrol treatment decreased the levels of $\beta$-catenin proteins in a dose-dependent manner (Fig. 4B and C). The results indicate that SIRT1 negatively regulates $\beta$-catenin protein levels in human hepatic Hep3B cells.

Upregulation of SIRT1 enhances the sensitivity of Hep3B-HBX cells to doxorubicin-induced apoptosis. To examine how modulation of SIRT1 affects the viability of hepatic cells stably expressing HBX under stress conditions such as DNA damage, we first optimized the concentration of doxorubicin, an anticancer drug using Hep3B-Vec and Hep3B-HBX cells. As shown in Fig. 5A, Hep3B-HBX cells survived in up to
$500 \mu \mathrm{g} / \mathrm{ml}$ doxorubicin for $48 \mathrm{~h}$ while Hep3B-Vec cells were sensitive to $500 \mu \mathrm{g} / \mathrm{ml}$ doxorubicin. This result indicates that HBX confers resistance to doxorubicin. Using the Hep3B-HBX cells that exhibited resistance to doxorubicin, we next examined whether upregulation of SIRT1 enhances sensitivity to apoptosis during doxorubicin treatment. Hep3B-HBX cells were transfected with SIRT1-GFP and then incubated with doxorubicin $24 \mathrm{~h}$ after transfection. As shown in Fig. 5B, although introduction of GFP did not induce cell death of Hep3B-HBX cells during doxorubicin treatment, introduction of SIRT1-GFP enhanced doxorubicin-induced cell death. Furthermore, when Hep3B-HBX cells were treated with resveratrol in the presence of doxorubicin, the cells exhibited 
greater sensitivity to apoptosis than Hep3B-HBX cells treated with doxorubicin alone (Fig. 5C and D). Consistent with these results, combined treatment with resveratrol and doxorubicin reduced the number of surviving cells compared to doxorubicin treatment alone (Fig. 5E). The results indicate that upregulation of SIRT1 protein and activity enhances doxorubicin-induced apoptosis in Hep3B-HBX cells.

\section{Discussion}

The pleiotropic effects of HBX can be attributed to its promiscuous interaction with many host cellular factors including HIF1- $\alpha$ to adapt the HBV-infected hepatic cells to a hypoxic environment (42); Jab1 to activate AP1 transcription activity (43); and DNA methyltransferease to facilitate cellular epigenetic modification (44). Additionally, it has been shown that HBX binds to APC, a signaling molecule of the complex involved in Wnt-/ $\beta$-catenin signal transduction, which is involved in cell proliferation and tumor formation. HBX interacts with APC through a consensus domain necessary for APC binding to $\beta$-catenin, suggesting that HBX blocks $\beta$-catenin degradation by competitively displacing $\beta$-catenin from APC (45). Herein, we present a novel mechanism by which HBX sequesters SIRT1, thereby blocking SIRT1 inhibition of $\beta$-catenin in a Wnt signaling-independent manner. Therefore, this study provides evidence that $\beta$-catenin is superactivated, which could explain the oncogenic activity of HBX. We are investigating whether action of HBX toward SIRT1 is similar to the inhibitory action of HIV Tat protein toward SIRT1.

The roles of SIRT1 in tumor formation are controversial. Some studies have reported that SIRT1 can promote cancer cell growth by blocking cellular senescence through the direct deacetylation of p53 (19), Foxo (21), and E2F1 (46) and that overexpression of SIRT1 has been frequently detected in chemoresistant tumor cells and clinical tissues (47). In contrast, other groups have reported that increasing SIRT1 protein levels as a result of ectopic expression leads to reduced cell proliferation and tumor formation in a colon cancer model (40) and activation of SIRT1 activity by resveratrol also limits cell growth and reduces tumor formation in a breast cancer model (48). Subsequently, we explored the potential biological consequences of upregulating SIRT1 protein levels and activity in the presence of HBX. We discovered that upregulation of SIRT1 protein or activity enhances sensitivity of Hep3B-HBX cells to doxorubicin-induced apoptosis. In our HBX-induced hepatic cancer cell model, SIRT1 appears to act as a tumor suppressor, which is the opposite of its role in other studies which have shown that high SIRT1 activity promotes cell survival similar to an oncogene (49-51). Therefore, this result indicates that upregulation of SIRT1 proteins or activity could be a therapeutic strategy in HBX-induced hepatocellular carcinoma.

\section{Acknowledgements}

This study was supported by grants from the National Research Foundation (NRF) of Korea funded by the Ministry of Education, Science and Technology (2010-0020950) and by the World Class University program through the NRF funded by the Korean government (R31-2008-000-20004-0).

\section{References}

1. Neuveut C, Wei Y and Buendia MA: Mechanisms of HBV-related hepatocarcinogenesis. J Hepatol 52: 594-604, 2010.

2. Lupberger J and Hildt E: Hepatitis B virus-induced oncogenesis. World J Gastroenterol 13: 74-81, 2007.

3. Waris G, Huh KW and Siddiqui A: Mitochondrially associated hepatitis B virus $\mathrm{X}$ protein constitutively activates transcription factors STAT-3 and NF-kappa B via oxidative stress. Mol Cell Biol 21: 7721-7730, 2001.

4. Kekulé AS, Lauer U, Weiss L, Luber B and Hofschneider PH: Hepatitis B virus transactivator HBx uses a tumour promoter signalling pathway. Nature 361: 742-745, 1993.

5. Lee YH and Yun Y: HBx protein of hepatitis B virus activates Jak1-STAT signaling. J Biol Chem 273: 25510-25515, 1998.

6. Lee YI, Kang-Park S, Do SI and Lee YI: The hepatitis B virus-X protein activates a phosphatidylinositol 3-kinase-dependent survival signaling cascade. J Biol Chem 276: 16969-16977, 2001.

7. Yun C, Cho H, Kim SJ, Lee JH, Park SY, Chan GK and Cho H: Mitotic aberration coupled with centrosome amplification is induced by hepatitis B virus $\mathrm{X}$ oncoprotein via the Ras-mitogen-activated protein/extracellular signal-regulated kinase-mitogen-activated protein pathway. Mol Cancer Res 2: $159-169,2004$.

8. Kim H, Lee YH, Won J and Yun Y: Through induction of juxtaposition and tyrosine kinase activity of Jak1, X-gene product of hepatitis B virus stimulates Ras and the transcriptional activation through AP-1, NF-kappaB, and SRE enhancers. Biochem Biophys Res Commun 286: 886-894, 2001.

9. Park EH, Koh SS, Srisuttee R, Cho IR, Min HJ, Jhun BH, Lee YS, Jang KL, Kim CH, Johnston RN and Chung YH: Expression of HBX, an oncoprotein of hepatitis B virus, blocks reoviral oncolysis of hepatocellular carcinoma cells. Cancer Gene Ther 16: 453-461, 2009.

10. Cho IR, Oh M, Koh SS, Malilas W, Srisuttee R, Jhun BH, Pellegrini S, Fuchs SY and Chung YH: Hepatitis B virus X protein inhibits extracellular IFN- $\alpha$-mediated signal transduction by downregulation of type I IFN receptor. Int J Mol Med 29: 581-586, 2012.

11. Chen J and Siddiqui A: Hepatitis B virus X protein stimulates the mitochondrial translocation of Raf-1 via oxidative stress. J Virol 81: 6757-6760, 2007.

12. Srisuttee R, Koh SS, Park EH, Cho IR, Min HJ, Jhun BH, Yu DY, Park S, Park do Y, Lee MO, et al: Up-regulation of Foxo4 mediated by hepatitis B virus $\mathrm{X}$ protein confers resistance to oxidative stress-induced cell death. Int J Mol Med 28: 255-260, 2011.

13. Brooks CL and Gu W: How does SIRT1 affect metabolism, senescence and cancer? Nat Rev Cancer 9: 123-128, 2009.

14. Lin SJ, Defossez PA and Guarente L: Requirement of NAD and SIR2 for life-span extension by calorie restriction in Saccharomyces cerevisiae. Science 289: 2126-2128, 2000.

15. Rogina B and Helfand SL: Sir2 mediates longevity in the fly through a pathway related to calorie restriction. Proc Natl Acad Sci USA 101: 15998-16003, 2004.

16. Tissenbaum HA and Guarente L: Increased dosage of a sir-2 gene extends lifespan in Caenorhabditis elegans. Nature 410: 227-230, 2001

17. Vaquero A, Scher M, Lee D, Erdjument-Bromage H, Tempst $P$ and Reinberg D: Human SirT1 interacts with histone H1 and promotes formation of facultative heterochromatin. Mol Cell 16: 93-105, 2004.

18. Yeung F, Hoberg JE, Ramsey CS, Keller MD, Jones DR, Frye RA and Mayo MW: Modulation of NF-kappaB-dependent transcription and cell survival by the SIRT1 deacetylase. EMBO J 23: 2369-2380, 2004.

19. Luo J, Nikolaev AY, Imai S, Chen D, Su F, Shiloh A, Guarente L and $\mathrm{Gu}$ W: Negative control of p53 by Sir2alpha promotes cell survival under stress. Cell 107: 137-148, 2001.

20. Cohen HY, Miller C, Bitterman KJ, Wall NR, Hekking B, Kessler B, Howitz KT, Gorospe M, de Cabo R and Sinclair DA: Calorie restriction promotes mammalian cell survival by inducing the SIRT1 deacetylase. Science 305: 390-392, 2004.

21. Brunet A, Sweeney LB, Sturgill JF, Chua KF, Greer PL, Lin Y, Tran H, Ross SE, Mostoslavsky R, Cohen HY, et al: Stressdependent regulation of FOXO transcription factors by the SIRT1 deacetylase. Science 303: 2011-2015, 2004.

22. Kim JE, Chen J and Lou Z: DBC1 is a negative regulator of SIRT1. Nature 451: 583-586, 2008 
23. Zhao W, Kruse JP, Tang Y, Jung SY, Qin J and Gu W: Negative regulation of the deacetylase SIRT1 by DBC1. Nature 451 : 587-590, 2008

24. Kim EJ, Kho JH, Kang MR and Um SJ: Active regulator of SIRT1 cooperates with SIRT1 and facilitates suppression of p53 activity. Mol Cell 28: 277-290, 2007.

25. Kwon HS, Brent MM, Getachew R, Jayakumar P, Chen LF, Schnolzer M, McBurney MW, Marmorstein R, Greene WC and Ott M: Human immunodeficiency virus type 1 Tat protein inhibits the SIRT1 deacetylase and induces T cell hyperactivation. Cell Host Microbe 3: 158-167, 2008.

26. Peifer M and Polakis P: Wnt signaling in oncogenesis and embryogenesis - a look outside the nucleus. Science 287: 1606-1609, 2000

27. Huelsken $J$ and Birchmeier W: New aspects of Wnt signaling pathways in higher vertebrates. Curr Opin Genet Dev 11: 547-553, 2001.

28. Giles RH, van Es JH and Clevers H: Caught up in a Wnt storm: Wnt signaling in cancer. Biochim Biophys Acta 1653: 1-24, 2003.

29. Polakis P: Casein kinase 1: a Wnt'er of disconnect. Curr Biol 12: R499-R501, 2002.

30. Morin PJ: $\beta$-catenin signaling and cancer. Bioessays 21: 1021-1030, 1999.

31. Tetsu O and McCormick F: Beta-catenin regulates expression of cyclin D1 in colon carcinoma cells. Nature 398: 422-426, 1999.

32. He TC, Sparks AB, Rago C, Hermeking H, Zawel L, da Costa LT, Morin PJ, Vogelstein B and Kinzler KW: Identification of c-MYC as a target of the APC pathway. Science 281: 1509-1512, 1998.

33. He TC, Chan TA, Vogelstein B and Kinzler KW: PPAR $\delta$ is an APC-regulated target of nonsteroidal anti-inflammatory drugs. Cell 99: 335-345, 1999.

34. Saadeddin A, Babaei-Jadidi R, Spencer-Dene B and Nateri AS The links between transcription, beta-catenin/JNK signaling, and carcinogenesis. Mol Cancer Res 7: 1189-1196, 2009.

35. Tanno M, Sakamoto J, Miura T, Shimamoto K and Horio Y: Nucleocytoplasmic shuttling of the $\mathrm{NAD}^{+}$-dependent histone deacetylase SIRT1. J Biol Chem 282: 6823-6832, 2007.

36. Yuan Z, Zhang X, Sengupta N, Lane WS and Seto E: SIRT1 regulates the function of the Nijmegen breakage syndrome protein. Mol Cell 27: 149-162, 2007.

37. Park S, Gwak J, Cho M, Song T, Won J, Kim DE, Shin JG and Oh S: Hexachlorophene inhibits Wnt/beta-catenin pathway by promoting Siah-mediated beta-catenin degradation. Mol Pharmacol 70: 960-966, 2006.

38. Cha MY, Kim CM, Park YM and Ryu WS: Hepatitis B virus $\mathrm{X}$ protein is essential for the activation of Wnt/beta-catenin signaling in hepatoma cells. Hepatology 39: 1683-1693, 2004.

39. Rahman S and Islam R: Mammalian Sirt1: insights on its biological functions. Cell Commun Signal 9: 11, 2011.

40. Firestein R, Blander G, Michan S, Oberdoerffer P, Ogino S, Campbell J, Bhimavarapu A, Luikenhuis S, de Cabo R, Fuchs C, et al: The SIRT1 deacetylase suppresses intestinal tumorigenesis and colon cancer growth. PLoS One 3: e2020, 2008.
41. Wang RH, Zheng Y, Kim HS, Xu X, Cao L, Luhasen T, Lee MH, Xiao C, Vassilopoulos A, Chen W, et al: Interplay among BRCA1, SIRT1, and Survivin during BRCA1-associated tumorigenesis. Mol Cell 32: 11-20, 2008

42. Moon EJ, Jeong CH, Jeong JW, Kim KR, Yu DY, Murakami S, Kim CW and Kim KW: Hepatitis B virus X protein induces angiogenesis by stabilizing hypoxia-inducible factor-lalpha. FASEB J 18: 382-384, 2004.

43. Tanaka Y, Kanai F, Ichimura T, Tateishi K, Asaoka Y, Guleng B, Jazag A, Ohta M, Imamura J, Ikenoue T, et al: The hepatitis B virus $X$ protein enhances AP-1 activation through interaction with Jabl. Oncogene 25: 633-642, 2006.

44. Jung JK, Arora P, Pagano JS and Jang KL: Expression of DNA methyltransferase 1 is activated by hepatitis B virus $X$ protein via a regulatory circuit involving the p16INK4a-cyclin D1-CDK 4/6-pRb-E2F1 pathway. Cancer Res 67: 5771-5778, 2007.

45. Hsieh A, Kim HS, Lim SO, Yu DY and Jung G: Hepatitis B viral $\mathrm{X}$ protein interacts with tumor suppressor adenomatous polyposis coli to activate $\mathrm{Wnt} / \beta$-catenin signaling. Cancer Lett 300: 162-172, 2011.

46. Yang Y, Fu W, Chen J, Olashaw N, Zhang X, Nicosia SV, Bhalla K and Bai W: SIRT1 sumoylation regulates its deacetylase activity and cellular response to genotoxic stress. Nat Cell Biol 9: 1253$1262,2007$.

47. Chu F, Chou PM, Zheng X, Mirkin BL and Rebbaa A: Control of multidrug resistance gene mdr1 and cancer resistance to chemotherapy by the longevity gene sirt1. Cancer Res 65: 10183-10187, 2005.

48. Wang RH, Sengupta K, Li C, Kim HS, Cao L, Xiao C, Kim S, $\mathrm{Xu} \mathrm{X}$, Zheng Y, Chilton B, et al: Impaired DNA damage response, genome instability, and tumorigenesis in SIRT1 mutant mice. Cancer Cell 14: 312-323, 2008.

49. Huffman DM, Grizzle WE, Bamman MM, Kim JS, Eltoum IA, Elgavish A and Nagy TR: SIRT1 is significantly elevated in mouse and human prostate cancer. Cancer Res 67: 6612-6618, 2007.

50. Bradbury CA, Khanim FL, Hayden R, Bunce CM, White DA, Drayson MT, Craddock C and Turner BM: Histone deacetylases in acute myeloid leukaemia show a distinctive pattern of expression that changes selectively in response to deacetylase inhibitors. Leukemia 19: 1751-1759, 2005.

51. Stünkel W, Peh BK, Tan YC, Nayagam VM, Wang X, Salto-Tellez M, Ni B, Entzeroth M and Wood J: Function of the SIRT1 protein deacetylase in cancer. Biotechnol J 2: 1360-1368, 2007.

52. Cho IR, Jeong S, Jhun BH, An WG, Lee B, Kwak YT, Lee SH, Jung JU and Chung YH: Activation of non-canonical NF-kappaB pathway mediated by STP-A11, an oncoprotein of Herpesvirus saimiri. Virology 359: 37-45, 2007. 